\title{
Ausencia de justicia e imposibilidad de reconciliación en el cine del posconflicto peruano
}

\author{
Justice absence and the impossibility of reconciliation \\ on the post IAC Peruvian movies
}

\section{James Dettleff*}

\footnotetext{
* Docente de la Pontificia Universidad Católica del Perú. Comunicador social con especialización en Medios Audiovisuales (Universidad de Lima). Master of Fine Arts en Cine (Ohio University). Candidato doctoral (Universidad Católica de Chile).

$\varangle$.jdettleff@pucp.edu.pe https://orcid.org/0000-00023603-1699
}

RECIBIDO: 13.4 .2020

ACEPTADO: 26.5.2020

\section{Resumen}

Esta investigación analiza la manera en que la ausencia de justicia es representada en cinco películas peruanas realizadas durante el posconflicto armado interno. Como producto cultural, esta representación contribuye a generar memoria cultural sobre lo ocurrido en las últimas dos décadas del siglo pasado y participa en las condiciones para intentar la reconciliación en el país. Para destacar las formas en que la justicia es representada, y cómo se plantean las posibilidades de reconciliación a partir de ello, se presenta un repaso teórico breve del concepto de memoria cultural y las formas de justicia, y se emplea una metodología cualitativa para realizar análisis temáticos, análisis del texto cinematográfico y audiovisual, complementados con entrevistas a realizadores y personalidades relacionadas con el conflicto armado interno. Puede observarse que hay una coincidencia en los discursos cinematográficos en cuanto a la injusticia vivida en esos años, que continúa hasta el presente.

Palabras clave: memoria colectiva, guerra, Perú, cine.

\section{Abstract}

This paper focuses on how the absence of justice is represented in five Peruvian films produced after the internal armed conflict period. These representations 
contribute to cultural heritage preserving the memory of the events occurred during the last two decades of the 20th Century in Peru, fostering national reconciliation. To highlight the ways in which justice is represented and how the possibilities of reconciliation are addressed, a brief theoretical review of the concepts of cultural memory and forms of justice is presented. Qualitative methodology is used to analyse topics, scripts, and audio-visual language, complemented with interviews with filmmakers and personalities related to the armed conflict. The cinematographic discourses show coincidences regarding the injustice experienced during those years, which continues to these days. Keywords: collective memory, war, Perú, cinema.

\section{Introducción ${ }^{1}$}

El conflicto armado interno (CAI) peruano — que enfrentó al Estado peruano con los grupos terroristas Sendero Luminoso y Movimiento Revolucionario Túpac Amaru (MRTA) - se desarrolló entre los años 1980 y 2000, y, si bien se han dado medidas desde la oficialidad para intentar sanar las heridas, aún existen muchos elementos no resueltos que impiden un cierre adecuado. La manera en que se rememoran los hechos de esa época condiciona la forma en que se abordan estos problemas, que dieron origen al conflicto y se agudizaron durante su transcurso.

El necesario duelo que no se ha logrado hacer en los espacios políticos y sociales se está llevando a cabo en los espacios culturales. Más allá de una historia oficial, son los objetos culturales los que están desarrollando diferentes formas de mantener vivo el recuerdo de lo sucedido en esa época, principalmente en la zona más afectada por el terrorismo: Ayacucho.

El cine, como artefacto cultural masivo y móvil, es uno de los medios de representación más poderosos de la época del CAI. Producciones realizadas en Lima y en Ayacucho se han aproximado al tema y puesto en escena los elementos que agudizan el problema y que deben abordarse para intentar la reconciliación entre los peruanos.

Existe una posición testimonial en las películas, que aun siendo de ficción se presentan como documentos de lo acontecido, denuncian lo que pasó durante esos años y generan una versión de los hechos superpuesta a la historia oficial.

Para realizar este trabajo hemos adoptado una metodología cualitativa. Desde la finalización del CAI, en 1999, se han realizado en Lima y Ayacucho 14 películas de ficción. Elegimos trabajar con cinco que tratan directamente el CAI, considerando que son 
representativas de diferentes épocas de las dos décadas que han pasado y que pueden ofrecer el punto de vista de los realizadores ayacuchanos, limeños y de las fuerzas armadas. Las películas trabajadas son:

- Sangre inocente (Ortega, 2000). Cuenta la historia de Pochito (Alfonso) y sus sobrinos Pepito y Cirilo, quienes son acusados de ser terroristas. Pochito es detenido y llevado al centro de detención Casa Rosada, donde es torturado mientras sus sobrinos lo buscan.

- El rincón de los inocentes (Ortega, 2007). Relata la historia de Manuelito, un niño cuyo hermano llega moribundo a su casa en Ayacucho y cuyos padres son desaparecidos al buscar justicia.

- Vidas paralelas (Lladó, 2008). Cuenta la historia de Felipe y Sixto. Cuando son adolescentes, una columna de Sendero Luminoso entra al pueblo donde viven, matan al padre de Felipe y secuestran a Sixto. Felipe se convertirá en militar, mientras que Sixto se volverá un cabecilla senderista.

- Magallanes (Del Solar, 2015). Es la historia de un excombatiente del CAI que un día en Lima reconoce a Celina, la mujer a quien Avelino — comandante de Magallanesretuvo como esclava sexual en Ayacucho años atrás. Intentando limpiar sus culpas y ayudarla, Magallanes decide conseguir dinero extorsionando al hijo de Avelino.

- La última noticia (Legaspi, 2015). Relata la vida de Alonso, un periodista de la ciudad andina de Yurabamba que empieza a narrar lo que va sucediendo en la zona, y de Pedro, profesor de colegio. Ambos personajes son amenazados tanto por Sendero Luminoso como por las fuerzas del orden.

Metodológicamente hemos hecho un análisis temático de estas películas, así como un análisis del texto cinematográfico y audiovisual. Para ello nos hemos enfocado en los personajes, pues son quienes desarrollan la acción dramática, y es a través de ellos que conocemos los hechos y las sensaciones de injusticia. En el análisis se trabajaron las circunstancias que generan una situación criminal, de abuso o de exceso de poder, las desatenciones jurídicas y las acciones que ejecutan los personajes para lograr algún tipo de resarcimiento. La siguiente etapa consistió en un trabajo comparativo para encontrar temas y situaciones en común, así como diferencias. Finalmente entrevistamos a los realizadores.

\section{Los productos culturales como productores de memoria}

El cine es un medio que con sus imágenes e historias puede ayudar a reconstituir el pasado y construir una memoria sobre él. Sus cualidades dramáticas pueden lograr 
que hechos vividos previamente se vuelvan un elemento actual, sin las barreras de la memoria. Se puede generar una presentización del acontecimiento al experimentar distintos elementos aislados que son producidos por una memoria involuntaria y generan sentido al volverse nuestra memoria (Benjamin, 1929, pp. 6-7).

Hoskins (2001) indica que la memoria es una (re)construcción, para la cual se generará una representación que creará sentido a los sujetos, dependiendo de lo que se recuerde y conforme a la interpretación que esa representación tenga en el momento presente (Ankersmit, 1988; Birulés, 1989). Erll (2008) indica que, cuando aquellos que fueron protagonistas de los hechos o testigos de los acontecimientos vayan desapareciendo, la memoria dependerá de otros elementos para trasmitir la experiencia de aquello que se vivió. Será necesario entonces que existan prácticas y productos mnemónicos que, al ser utilizados, interpretados y reproducidos, logren un estatus de realidad (Olick, 2008). El trabajo de Nora pone de manifiesto la existencia de memoriales, archivos, fiestas, etcétera, a los que el autor llama restos, los cuales se convierten en productos mnemónicos que generan rituales para la memoria (Nora, 2008, p. 24). En el Perú, en diversos pueblos y ciudades, hay lugares, espacios, restos que marcan con una placa o inscripción un hecho, un rezago de lo que ahí ocurrió, como productos que buscan que se reconstruya una época pasada. Tal como lo afirma Nora, están ahí porque saben que «no hay memoria espontánea», sino que esta debe ser activada a partir de esos restos (Nora, 2008, p. 25).

La memoria se articula de esta forma gracias a objetos e imágenes que generan procesos de representación, y se convierten en tecnologías de la memoria en el sentido foucaultiano, es decir, entendidas como dinámicas sociales más allá de los objetos, que implican negociaciones de poder productoras de sentido (Sturken, 1997b, p. 9).

Para Halbwachs los individuos adquieren sus memorias en la sociedad, y es en ella donde las reconocen y localizan (Halbwachs, 1992). Esta memoria provee identidad al grupo (Halbwachs, 1995; Ricoeur, 1999; Sturken, 1997), que compone de manera colectiva el pasado de una forma que resulte acorde con los pensamientos dominantes de la sociedad actual (Halbwachs, 2004, p. 10). El cine se vuelve así en un elemento que aglutina, da sentido e identidad a un grupo determinado.

No entraremos aquí en las discusiones sobre memoria colectiva, social o histórica, que tienen larga data. En este trabajo preferimos el concepto de memoria cultural, el cual subraya que esa memoria es compartida fuera del discurso histórico formal, a través de productos culturales que contienen un orden simbólico y prácticas sociales que en su construcción generan un sentido en la colectividad (Erll, 2008; Sturken, 1997). La memoria cultural se produce a través de representaciones e involucra la interacción de los individuos en la creación de significación cultural, mediante negociaciones que buscan su lugar en la historia (Sturken, 1997, p. 1). 
Vich (2015) indica que el informe de la Comisión de la Verdad y la Reconciliación (CVR) ha tenido una repercusión importante en el campo de la cultura, y sus principales conclusiones están circulando en la dinámica social. Películas, obras de teatro, artesanías y otros productos culturales reflejan lo que este relato contiene.

El cine de posconflicto peruano se constituye de esta manera en tecnología de memorias a partir de la representación que hace sobre esa época. Los relatos audiovisuales basados en hechos reales se convierten en un producto generador de memoria cultural, un relato del pasado que permite reconstruirlo desde una perspectiva particular, de acuerdo a los marcos sociales y culturales dominantes en la sociedad en el momento en que se producen.

Jelin indica que para fijar ciertos parámetros de identidad se seleccionan algunos hitos que se convertirán en elementos invariantes, alrededor de los cuales se organizan las memorias (Jelin, 2001, p. 7). En el conflicto peruano se dieron muchos hechos de violencia y de violación de derechos humanos, en distintas partes del Perú y en diferentes comunidades de sujetos.

\section{Los procesos de justicia}

La ausencia de justicia es un tema recurrente en la gran mayoría de las películas del corpus trabajado. Frente a un conflicto con un alto número de víctimas y que dividió al país, lo que se espera es que se cierre con el señalamiento de los culpables y con juicios que lleven a reparar el daño causado a las víctimas.

El derecho a la justicia impone al Estado la obligación de investigar las violaciones, la de perseguir a sus autores y la de asegurar su sanción una vez establecida la culpabilidad en orden a la prevención, es decir, a la no repetición de la barbarie. (Sampedro-Arrubla, 2010, p. 101)

Ese fue el espíritu por el cual en el Perú se conformó la CVR. Los comisionados entendieron que «la satisfacción de la justicia implica la determinación de responsabilidades», pero hubo limitaciones que impidieron dar pasos concretos para lograr justicia, pues «la CVR no contó con facultades jurisdiccionales» (Comisión de la Verdad y la Reconciliación [CVR], 2004, p. 34).

Salomón Lerner, presidente de la CVR, afirmó que, cuando sucedieron los hechos del conflicto armado interno, la «estructura institucional para el cambio - y no para la conservación de las injusticias - no existía en el Perú en ese entonces y no existe por desgracia todavía» (CVR, 2004, p. III). Frente a un suceso como el CAI, la esperanza de 
las víctimas de obtener justicia es entendible, y el hecho de que esta no haya sido conseguida o se haya demorado es desesperanzador.

Diez años después, la situación no ha variado mucho, tal como afirma una dirigente de la Asociación Nacional de Familiares de Secuestrados, Detenidos y Desaparecidos del Perú (ANFASEP). «Hasta ahora seguimos buscando la verdad y la justicia» (A. García, comunicación personal, 18 de setiembre del 2018). Luis Berrocal, director de cine ayacuchano, indica la sensación de falta de justicia en la época del CAI:

Nunca hemos visto que haya un juicio sobre eso. Desapareció, lo mataron y era normal. [...] No hay justicia, no hubo justicia, nunca se buscó a los culpables. (L. E. Berrocal, comunicación personal, 24 de noviembre de 2018)

Márquez subraya algunos derechos establecidos por la ONU, como el derecho que tienen las víctimas de conocer las circunstancias de las violaciones, el fallecimiento o la desaparición de las personas (derecho a saber) y la obligación de los Estados de investigar, procesar y condenar a los responsables (derecho a la justicia) (Márquez, 2009, p. 61). En las declaraciones de García y Berrocal, ambos derechos han sido violentados y hasta el momento no han logrado recuperarlos.

Honneth observa que para prevenir los conflictos sociales es necesario el reconocimiento recíproco de los individuos, en relaciones de amor o amistad, jurídico y de solidaridad (Honneth, 1997, p. 116), e indica que a estos reconocimientos se les contraponen modos de desprecio que son el maltrato y el daño a la integridad física, la desposesión de derechos y el daño al honor y la dignidad (Honneth, 1997, p. 159). De esta manera, al no desarrollarse relaciones de amor o amistad, el conflicto deviene en un modo de desprecio que lleva al maltrato o al daño a la integridad física. Al no desarrollarse un reconocimiento de solidaridad, se dan daños al honor y la dignidad de las personas. A esto se suma la falta de un reconocimiento recíproco de lo jurídico, que lleva a la desposesión de derechos de aquellos que fueron afectados.

En su trabajo sobre formas de memoria de la masacre de Accomarca, Renzo Aroni observa: «La búsqueda de justicia y reparación por los familiares de las víctimas y de los sobrevivientes los condujo a organizar otras formas de recordar, protestar y exigir justicia, como son las canciones y la coreografía carnavalesca» (Aroni, 2015, p. 123). La memoria cultural es de esta forma una manera no solo de preservar el recuerdo de lo ocurrido, sino de exigir que se haga justicia, manteniendo presentes los hechos que el Estado parece dejar de lado, con procesos lentos y largos que no aportan a la sensación de justicia. ${ }^{2}$ 
En un país como el Perú, con un Poder Judicial anticuado, lento y desigual, y en la actualidad altamente cuestionado ante los destapes de corrupción, las formas de memoria cultural son la manera en que la población busca justicia, luego de décadas de formas violentas. Las películas con que trabajamos en esta investigación aportan en esa línea.

El concepto de justicia se relaciona con el de sanción y condena, con el hecho de castigar a los delincuentes o perpetradores. Para Hernández, es un sistema de justicia que en nuestro continente proviene de épocas coloniales, y se nutre de un conocimiento y adaptación de los «sistemas políticos y jurídicos de los pueblos colonizados para su mejor control y dominación» (Hernández, 2017, p. 54).

Podríamos preguntarnos si el castigo impone realmente justicia. Hay quienes cuestionan esta forma de justicia e indican: «Una de las cosas más chocantes en el debate iusacadémico sobre la justicia, es el supuesto de que justicia ordenada por sentencia equivale a justicia suministrada» (Braithwaite, 2008, p. 5). El autor es parte de una corriente diferente, que propone la justicia restaurativa, donde el enfoque está en la reparación de las relaciones humanas, una reparación que no se basa tanto en lo económico o en el castigo, sino que busca reconocer la falta y perdonar.

En la justicia restaurativa hay un reconocimiento de quien ha cometido el delito y hay un pedido de disculpas, lo cual es un primer movimiento hacia la reconciliación. La CVR dio pasos para que se trabajara en lo último, pero no tuvo el ámbito suficiente, como sí lo tuvo la CVR de Sudáfrica, donde los victimarios confesaron sus crímenes y fueron las víctimas quienes en muchos casos determinaron si debía indultárselos o no. «En comparación con los procesos de control, la víctima se ve más robustecida en su convicción de que sus derechos son respetados y de que se ha hecho justicia» (Braithwaite, 2008, p. 3).

\section{La justicia en las películas del corpus}

La ausencia de justicia se da frente a un hecho de violencia o abuso en la que aquellos que lo sufren no encontrarán una situación que pueda resarcirlos. Esto hace que los personajes se vean como individuos a quienes se les limitan o eliminan sus derechos fundamentales.

Los personajes representados en las películas como ausentes de derecho son en su mayoría sujetos andinos, a quienes se priva de libertad o se mata impunemente, como elementos sin valor para la sociedad, sin capacidad de lograr justicia.

En regímenes de violencia, la desaparición forzada es uno de los delitos más recordables cometidos por las fuerzas involucradas. Los informes de diferentes comisio- 
nes en países como Chile, Argentina, Sudáfrica o Guatemala dan cuenta de personas secuestradas y detenidas de las cuales no se vuelve a saber. El caso peruano no es diferente, y las películas del corpus reflejan eso con diferentes personajes.

Las acciones en que uno o más personajes desaparecen o son secuestrados son de lo más recurrente entre las películas del corpus de análisis: Pochito (Sangre inocente), Sixto (Vidas paralelas), Manuel y Elena (El rincón de los inocentes), Celina y Augusto (Magallanes), Alonso y Pedro (La última noticia). En muchos casos, estos personajes no vuelven a aparecer, o sus cadáveres son encontrados después. La muerte es un elemento que va de la mano de la desaparición o el secuestro, y estas acciones nunca son resarcidas por algún acto de justicia o reparación.

Frente a los miembros de la Delegación de la Verdad, uno de los personajes clama por los restos de su hijo. "iAyúdenme a encontrar a mi hijo! Aunque sea sus huesitos quisiera ver, para dormir tranquila» (Josefina, El rincón de los inocentes, escena 59). Este pedido recalca que el daño que se hace no es solo a la persona que desaparece, sino a los familiares, que deben buscarlos con la angustia de no saber sobre su paradero y sin la posibilidad de un cierre que permita un camino distinto para iniciar la recuperación del trauma.

Otros personajes de las películas realizadas en Ayacucho verán cierta posibilidad de cierre al encontrar los cuerpos de sus seres queridos, como es el caso de Manuelito con respecto a su madre (El rincón de los inocentes) y Michel con respecto a su padre (Sangre inocente). Pero para ambos personajes también existirán ausencias, pues Manuelito nunca encontrará el cadáver de su padre, así como Michel nunca recuperará el cuerpo de su madre.

Cirilo y Pepito encuentran el cuerpo moribundo de su tío Pochito, lanzado a una quebrada (Sangre inocente). Los jóvenes han visto muchos otros cuerpos a lo largo del relato, cuerpos de personas desaparecidas y asesinadas, que quizá sean recuperadas por sus familiares. Pero la realidad es que esas personas nunca aparecen. Por ello, para los familiares de los desaparecidos, lograr formas de encontrar los restos de sus familiares es un primer paso en la búsqueda de justicia.

En algunos de los relatos fílmicos las detenciones arbitrarias y la desaparición de los cuerpos no son vistos en acciones, sino contados por algún personaje dentro del relato. Michel relata la desaparición de sus padres y Cirilo la de su vecino (Sangre inocente); nos enteramos de las desapariciones de varios pobladores a través del relato de sus familiares en la radio (La última noticia), así como nos enteramos de la detención por más de un año de Celina (Magallanes). Ninguna de esas situaciones muestra algún tipo de resolución legal; todas quedan como eventos donde no ha habido un acto de justicia luego de los hechos acontecidos. Es información que se nos brinda, pero sin solución. 
De la misma forma, en varios relatos la muerte que queda impune no se da necesariamente como consecuencia de las detenciones y desapariciones. Muchas muertes son mostradas en pantalla y, aunque para algunas no hay seguimiento del caso, se genera una sensación de muertes sin juicio, resarcimiento, búsqueda de culpables ni acción de justicia alguna.

En Sangre inocente se muestra el asesinato de un policía y de un sacerdote, al igual que de un detenido en la Casa Rosada, y al final de la película Michel será asesinado en la carretera, sin que ninguno de estos hechos tenga después alguna acción de justicia para las víctimas; en La última noticia, Pedro es asesinado al negarse a leer una proclama senderista en el colegio; Vidas paralelas representa el asesinato del padre de Felipe por el simple hecho de ser alcalde de su pueblo, mientras Carolina es asesinada por los senderistas, sin que nadie responda por esos asesinatos. El detonador del relato en El rincón de los inocentes es la muerte de Pedro - el hermano mayor de Manuelito-, un estudiante, en la puerta de su casa, cuyo asesinato no será siquiera investigado. Ninguna de estas muertes se ve judicializada, resuelta ni castigada.

Lo que observamos son diferentes relatos que plantean que ninguna de estas muertes o desapariciones se resolverán, no tendrán castigo para los culpables ni ningún tipo de reparación. Esto presenta una situación donde no solo no pude producirse un cierre adecuado para los familiares, sino que abre nuevas heridas que permiten repetir errores del pasado. «Cuando no hay revisión de la verdad ni hay satisfacción de los derechos de las víctimas, la sociedad queda - irremediablemente- condenada a repetir la barbarie, porque no hay enseñanza» (Sampedro-Arrubla, 2010, p. 98).

Otra forma en que se representa la ausencia de justicia en las películas es a partir de personajes que son acusados falsamente de algún crimen - en la mayoría de los casos, de ser terroristas - y personajes que no logran que sus reclamos sean atendidos por los órganos adecuados para impartir justicia.

En películas como Sangre inocente, las detenciones forzadas a las que nos hemos referido se relacionan directamente con una falsa acusación de terrorismo o de asesinato. Pochito, Pepito y Cirilo son acusados de terroristas, e incluso se muestra cómo los militares plantan falsas pruebas en su casa. En las escenas del centro de detención Casa Rosada, se ven otros prisioneros acusados sin pruebas, los cuales bajo tortura dan nombres de supuestos terroristas para lograr su libertad, con lo cual se generan falsos acusados.

Alonso y Pedro son tomados prisioneros y acusados falsamente en La última noticia. Lograrán su libertad gracias a la presión internacional de la prensa, pero no por algún proceso judicial o legal.

Cuando Enrique va a colocar la denuncia de la desaparición de su hijo, solo recibe la negativa de la fiscal, quien termina sugiriendo que Pedro seguro era terrorista. El consejo que recibe de otro funcionario es desesperanzador. «Nada podemos hacer. Estamos 
en Ayacucho. Cientos de muertos aparecen y no pasa nada. Déjelo así no más» (Funcionario de la fiscalía. El rincón de los inocentes, escena 12).

Ni la fiscalía, ni la policía, ni la Iglesia querrán aceptar las denuncias que tienen los personajes de este relato, y tampoco hacerse cargo de ellas ni llevar a cabo investigaciones. Cuando en Sangre inocente Michel intenta ayudar a Cirilo y Pepito hablando con un familiar que es fiscal, no logra siquiera que este recabe los datos del detenido.

Magallanes finaliza con hechos jurídicos irresueltos. A pesar de ser un violador, torturador y posible asesino, el coronel Avelino evitará toda acción en su contra por su condición de viejo senil y padre de un prestigioso abogado. El exmilitar Milton es también un violador, torturador y secuestrador, pero no recibirá castigo alguno. A pesar que al final desea que la ley caiga sobre él, el exmilitar Magallanes tampoco será juzgado por lo que le hizo a Celina ni por el chantaje y secuestro del abogado Augusto.

La búsqueda de la verdad y de la justicia queda de lado en este relato. Augusto no quiere saber ni que se sepa lo que su padre hizo en Ayacucho, Celina prefiere olvidar y que los demás olviden lo que pasó, y lo que queda entonces para Magallanes es la redención mediante el perdón o el castigo. Pero ni los afectados perdonarán ni la policía castigará, lo que deja al personaje deambulando alrededor del Palacio de Justicia, sin haber logrado un cierre sobre lo que la época del CAI significó para ellos.

En El rincón de los inocentes, Manuel ya adulto va a una audiencia de la Delegación de la Verdad y recrimina la insensibilidad de los delegados, su poca empatía y su desconocimiento de lo sucedido en Ayacucho. Los ve como seres foráneos, despreocupados realmente por lo que han escuchado. Su reclamo logra el aplauso de los pobladores presentes en la audiencia.

Junto con esta escena, la escena 64 de Magallanes, en la comisaría, es de las pocas que muestran algún acto de reivindicación para los personajes. Aunque ya hemos indicado que la sensación de desatención jurídica es más común y fuerte, en estas escenas hay algún tipo de empoderamiento de los personajes - Manuel y Celina- que les devuelve algo de valor.

La película Vidas paralelas, producida por el Comando Conjunto de las Fuerzas Armadas, plantea la injusticia de las muertes no resueltas ni castigadas en diferentes casos, y en lo jurídico plantea lo absurdo de juicios que determinaron culpables y responsables sin necesidad de presentar mayores pruebas, un reclamo común de las fuerzas del orden que ven en esto una situación injusta para sus miembros que combatieron el terrorismo.

Estas situaciones en las que no se determinan culpables, no se atienden jurídicamente las denuncias, en las que los procesos son alargados o tienen fallas legales, van de la mano con la búsqueda de la verdad o el deseo de redención. La búsqueda de desaparecidos por sus familiares no es solo el deseo de encontrar a la persona o sus restos, sino también la necesidad de saber qué es lo que sucedió con ella. 
Varios personajes tienen como objetivo de sus acciones saber qué es lo que está pasando o ha pasado con los suyos y en su entorno. Michel (Sangre inocente), cuando buscan entre los cadáveres, se pregunta varias veces «¿Quiénes serán?, ¿por qué los habrán matado?», llevando al público a preguntarse por lo que sucedió y sus razones.

Junto con él, Enrique, Elena y Josefina (El rincón de los inocentes) querrán conocer la verdad de lo que sucedió con sus familiares, por qué fueron detenidos y dónde se encuentran. Alonso (La última noticia) buscará siempre información, tratando de encontrar la verdad de lo que sucede en la zona de Yurabamba.

Son personajes que desean ejercer su derecho a saber. «El derecho a saber comprende el derecho a la verdad, como derecho individual de la víctima, como un derecho colectivo que hunde sus raíces en la historia» (Sampedro-Arrubla, 2010, p. 97).

Frente a la falta de judicialización, reparaciones o señalamiento de culpables, la denuncia, el ser escuchados, el poder buscar — por lo menos - la verdad reafirma el derecho de las víctimas y sus familiares, ubicándolos como sujetos de derecho. Los personajes de los relatos del corpus de esta investigación se enfrentan al sistema, que los excluye, no los reconoce como interlocutores válidos, los aplasta e impide un cierre de sus historias, un final que les permita avanzar. Solo superando estas exclusiones es posible intentar la reconciliación.

La imposibilidad de dialogar y de avanzar del país está presente en las películas analizadas para esta investigación. Se plantea la falta de justicia, se plantea la problemática, pero no las posibilidades de reconciliación. No es que se espere que una película plantee soluciones a un problema tan profundo, pero con muy pocos matices no se vislumbra un futuro reconciliado. Para muchos peruanos, pero especialmente los ayacuchanos, la falta de reconocimiento y justicia es uno de los escollos más difíciles para la reconciliación.

\section{Conclusiones}

Las películas observadas en este trabajo muestran diferentes maneras de ausencia de justicia, en representaciones que van desde lo gráfico y evidente hasta situaciones que afectan a la población. Los relatos incluyen situaciones que merecen reparaciones y castigos - asesinatos, torturas, violaciones sexuales - y en ningún caso hay algún tipo de justicia para las víctimas. La injusticia se representa con la inacción de las autoridades competentes, con la desatención de las denuncias o el no señalamiento de culpables.

Las personas entrevistadas en Ayacucho ponen énfasis en la justicia y en asumir responsabilidades, en ser reconocidas como sujetos de derecho a los que estos les han sido violentados. Si los procesos judiciales son difíciles y largos, el pedir perdón, el reconocer que se ha hecho daño es una parte de la justicia restaurativa que reubica a los 
actores de un conflicto. Pero las películas de este trabajo no proponen nada de eso. Los relatos cinematográficos producidos en Ayacucho denuncian a los culpables, los señalan desde la posición de víctimas, y existe una desesperanza acerca de lograr la justicia o alguna reconciliación. Esos temas están prácticamente ausentes, y las películas de Lima no son muy diferentes en este sentido.

Las películas llaman también la atención sobre las desapariciones, los falsos acusados y los detenidos sin pruebas. Se plantea que la injusticia no es solo para las personas que son víctimas directas de estas acciones, sino también para sus familiares, aquellos que deben intentar encontrarlas o ver como no pueden defenderse ante las arbitrariedades.

En el Perú muchos casos fueron finalmente judicializados, y luego de largos periodos se han logrado ya sentencias. Eso permite un cierre a varios de los familiares y genera culpables, reconocimientos de abusos, reparaciones civiles y, en algunos casos, sentenciados. Pero hay de todos modos cierta insatisfacción. «Es una justicia indiferente, una justicia lenta que, cuando uno la ve así, básicamente parece más bien impunidad» (S. Del Solar, comunicación telefónica, 5 de octubre de 2018).

El prejuicio y la impunidad en las películas trabajadas aquí se verá en como los personajes enfrentan situaciones de violación de sus derechos, algún acto de violencia o arbitrariedad, y buscan infructuosamente una respuesta o reparación. Esto se muestra en acciones, diálogos y escenas que explicitan la búsqueda de una respuesta legal, pero en otros casos la ausencia de justicia está mostrada a través de la resignación y el desánimo de los personajes ante los hechos que les han sucedido.

Lo que es notorio en las películas analizadas es que la gran mayoría de los pobladores representados que son falsamente acusados, detenidos, torturados o desaparecidos son personajes andinos. Esto permite observar que es un sistema desigual de aplicación o acceso a la justicia, que existía en la sociedad peruana desde antes y se profundizó de manera dramática en la época del conflicto.

Las películas hablan de una ausencia de justicia en la sociedad, más allá de la época del CAI. Y eso es aún más evidente cuando se representa la desatención jurídica. Hay que destacar de todos modos que, si bien la desatención de justicia se plantea hacia los sujetos civiles, las películas representan mayoritariamente situaciones de injusticia creadas por los sectores gubernamentales, pero también por Sendero Luminoso y mayoritariamente por las fuerzas armadas.

Aunque los relatos se proponen como denuncia de las acciones injustas, ningún caso propone reconciliación. La única historia que podría plantearla -Magallanesdesestima por todos los medios esa posibilidad. Celina ha llegado a un punto en que no espera ningún tipo de justicia ni compensación. Frente al ofrecimiento de dinero logrará lo único que puede anhelar en ese momento: decidir por sí misma, sin intervención de aquellos que siempre han determinado su destino. Celina no logra justicia, pero sí algún 
tipo de resarcimiento: el derecho de ser ella reconocida como persona. Más allá de eso, no hay nada posible.

Estos relatos no solo aportan a la construcción de una memoria sobre los hechos ocurridos, sino también sobre sus consecuencias y sus heridas, y dan a las ficciones valor de realidad. Son relatos más profundos en cuanto a generar una memoria de abusos, discriminaciones e injusticias cuando sus realizadores son ayacuchanos, ya que se encuadran en el marco social del cual provienen. Pero los realizadores de Lima coinciden en mucho de lo ofrecido por el relato ayacuchano, en congruencia con lo recogido por la CVR en su informe final.

La posibilidad de intentar una justicia restaurativa como en otros lugares se hace difícil para el caso del Perú, donde hay quienes no quieren reconocer sus acciones, no creen que deban pedir disculpas ni aceptar que lo que hicieron está mal. Así, para los relatos cinematográficos el planteamiento de justicia restaurativa está fuera de discusión, ya que no hay culpables que reconozcan sus acciones ni actores que los busquen y los castiguen.

Lo que queda como documento para la memoria en estas películas son diferentes violaciones de derechos humanos, injusticias y la imposibilidad de restauraciones o reconciliaciones. Observando la realidad peruana y lo planteado en las películas del corpus, la paz sostenible en el Perú no parece posible en el futuro mediato.

\section{Referencias}

Ankersmit, F. (1988). Historical representation. History and Theory, 27(3), 205-228. doi.org/10.2307/2504918.

Aroni, R. (2015). Coreografía de una matanza: Memoria y performance de la masacre de Accomarca en el carnaval ayacuchano en Lima, Perú. Anthropologica, 33(34), 119 146.

Benjamin, W. (1929). Una imagen de Proust. Recuperado de http://www.afoiceeomartelo.com.br/posfsa/Autores/Benjamin,\%20Walter/Benjamin,\%20Walter\%20\%20Una\%20imagen\%20de\%20Proust.PDF.

Birulés, F. (1989). Donde no hay narrador no hay historia. En A.C. Danto, Historia y narración: Ensayos de filosofía analítica de la historia (pp.11-22). Barcelona: Paidós (Pensamiento Contemporáneo, 5).

Braithwaite, J. (2008). Justicia restaurativa: Una visión democrático-republicana del derecho penal. Recuperado de http://www.sinpermiso.info/textos/justiciarestaurativa-una-visin-democrtico-republicana-del-derecho-penal. 
Comisión de la Verdad y la Reconciliación (2004). Hatun Willakuy: Versión abreviada del informe final de la Comisión de la Verdad y Reconciliación. Lima: Instituto de Democracia y Derechos Humanos.

del Solar, S. (dir.). (2015). Magallanes. [Película]. Lima, Perú: CEPA Audiovisual.

Erll, A. (2008). Cultural memory studies: An introduction. En A. Erll y A. Nünning (eds.), Cultural memory studies (pp. 1-15). Berlín: De Gruyter

Halbwachs, M. (1992). On collective memory. Chicago: University of Chicago Press.

Halbwachs, M. (1995). Memoria colectiva y memoria histórica. Reis: Revista Española de Investigaciones Sociológicas, 69(95), 209-219. doi.org/10.2307/40183784.

Halbwachs, M. (2004). Los marcos sociales de la memoria. México: Anthropos.

Hernández, R. A. (2017). Activismo legal y talleres penitenciarios: Las paradojas de la antropología jurídica feminista y del trabajo cultural en espacios de reclusión. En R.A. Hernández (coord.), Resistencias penitenciarias: Investigación activista en espacios de reclusión (pp. 51-81). México: Juan Pablos Editor.

Honneth, A. (1997). La lucha por el reconocimiento. Barcelona: Crítica.

Hoskins, A. (2001). New memory: Mediating history. Historical Journal of Film, Radio and Television, 21(4), 333-346. doi.org/10.1080/01439680120075473.

Jelin, E. (2001). Los trabajos de la memoria. Madrid: Siglo XXI.

Legaspi, A. (dir.). (2015). La última noticia. [Película]. Lima, Perú: Grupo Chaski, Impossible Films.

Lladó, R. (dir.). (2008). Vidas paralelas. [Película]. Lima, Perú: Universidad Alas Peruanas.

Márquez, A. (2009). La doctrina social sobre la justicia restaurativa. Prolegómenos: Derechos y Valores, 12(24), 59-75. Recuperado de http://www.redalyc.org/pdf/876/87617269005.pdf.

Nora, P. (2008). Pierre Nora en Les lieux de mémorie. Montevideo: Trilce.

Olick, J. (2008). From collective memory to the sociology of mnemonic practices and products. En A. Erll y A. Nünning (eds.), Cultural memory studies (pp. 151-162). Berlín: De Gruyter.

Ortega, P. (dir.). (2000). Sangre inocente. [Película]. Ayacucho, Perú: Kactus Producción Cinematográfica, Vision Creative Films.

Ortega, P. (dir.). (2007). El rincón de los inocentes. [Película]. Ayacucho, Perú: Perú Movie, Andina Compañía Cinematográfica.

Ricoeur, P. (1999). La lectura del tiempo pasado: Memoria y olvido. Madrid: Arrecife.

Sampedro-Arrubla, J. (2010). La justicia restaurativa: Una nueva vía, desde las víctimas, en la solución al conflicto penal. International Law: Revista Colombiana de Derecho Internacional, (17), 1-38.

Sturken, M. (1997). Tangled memories: The Vietnam War, the AIDS epidemic, and the politics of remembering. Berkley: University of California Press. 
Vich, V. (2015). Poéticas del duelo. Lima: Instituto de Estudios Peruanos. 